\title{
Role of childhood health in the explanation of socioeconomic inequalities in early adult health
}

\author{
$\mathrm{H}$ van de Mheen, K Stronks, C W N Looman, J P Mackenbach
}

\begin{abstract}
Study objective-To examine the contribution of childhood health to the explanation of socioeconomic inequalities in health in early adult life.

Design-Retrospective data were used, which were obtained from a postal survey in the baseline of a prospective cohort study (the Longitudinal Study on SocioEconomic Health Differences in the Netherlands). Adult socioeconomic status was indicated by educational level, while health was indicated by perceived general health. Childhood health was measured by self reported periods of severe disease in childhood. Relations were analysed using logistic regression models. The reduction in odds ratios of "less than good" perceived general health for different educational groups after adjustment for childhood health was used to estimate the contribution of childhood health.
\end{abstract}

Setting-The population of the city of Eindhoven and surroundings in the south east of the Netherlands in 1991.

Participants-2511 respondents, aged 25-34 years, men and women, of Dutch nationality, were included in the analysis. Main results-There was a clear association between childhood health and adult health, as well as an association between childhood health and adult socioeconomic status. Approximately $5 \%$ to $10 \%$ of the increased risk of the lower socioeconomic groups of having a "less than good" perceived general health can be explained by childhood health.

Conclusions-Childhood health contributes to the explanation of socioeconomic inequalities in early adult health. Although this contribution is not very large, it cannot be ignored and has to be interpreted largely in terms of selection on health.

(F Epidemiol Community Health 1998;52:15-19)

Department of Public Health, Erasmus

University, PO Box 1738, 3000 DR

Rotterdam, the

Netherlands

$\mathrm{H}$ van de Mheen

K Stronks

C W N Looman

J P Mackenbach

Correspondence to:

Dr van de Mheen.

Accepted for publication 7 March 1997

During this century, impressive improvements have been made in the areas of health and physical development of children. ${ }^{1}$ It is generally accepted that higher standards of living, advances in sanitation and nutrition are the major determinants of these improvements. ${ }^{1-3}$ However, socioeconomic inequalities in health among children still exist in developed societies, and these have changed surprisingly little. ${ }^{145}$

Socioeconomic inequalities in health among children may have an impact in adult life in terms of the effect that they could have on socioeconomic health differences (SEHD) among the adult population. However, it is still unknown to what extent this plays a part.

The impact of childhood health on class differences in health among adults may act in two different ways: social causation and health selection. In the theory of social causation ${ }^{6}$ childhood health may contribute to the explanation of SEHD in adult life by the following mechanism. Children from families with lower socioeconomic status (SES) are likely to become lower SES adults, children from lower SES families are less healthy, and childhood illness is related to health status in adult life. ${ }^{7}$

In addition there may also be an effect of childhood health by means of health selection. The selection mechanism assumes health related social mobility: health problems in childhood influence the socioeconomic status when adult life begins. Evidence about the importance of social mobility related to health in childhood is however ambiguous. ${ }^{6-13}$

Evidence for the contribution of childhood health to the explanation of SEHD in adult life is mainly of an indirect nature. Hardly any direct research has been undertaken to study the importance of this contribution. Examples of these rare studies are the British birth cohort studies. Adjustment for childhood health (at the ages of 7 and 11) did not reduce class differences in health in early adulthood (age 23), ${ }^{14}$ but some reduction occurred after adjustment for health in adolescence. Results from the first British cohort study ${ }^{15}$ however show that serious illness in childhood explained a part of the social class differences in health status at age 36 .

In the Longitudinal Study of SocioEconomic Health Differences (LS-SEHD) retrospective data are available to investigate this issue for the age group 25-34 years in the Netherlands. The research question is the following: "What is the contribution of health in childhood to the explanation of SEHD in early adult life?"

In the LS-SEHD the contribution of several aspects of childhood health is directly measured by questions on disease and hospital admission in childhood. This study offers the opportunity to explore the contribution of childhood health to socioeconomic inequalities in adult health for different (adult) health indicators and different measures of socioeconomic status.

\section{Methods}

The design and objective of the LS-SEHD have been described in detail elsewhere. ${ }^{16}$ The study is based on a cohort of $15-74$ year old, 
non-institutionalised Dutch nationals who live in the city of Eindhoven and surroundings (a region in the south east of the Netherlands). At the time of the start of the survey a random sample of about 27000 people was drawn from the population registries of the participating municipalities, stratified by age and postcode (45-74 year old people and people from the highest and lowest SES groups, as indicated by postcode, were overrepresented). In this analysis cross sectional data were used, which were obtained from a postal survey in the baseline measurement (1991). The response rate was $70.1 \%$, which resulted in a study population of 18973 respondents. There were no significant differences in response rate with respect to sex, age, marital status, degree of urbanisation, and socioeconomic status (measured by postcode).

In this analysis, early adulthood was defined as the period between 25 and 34 years. Older age groups were not analysed because of considerable recall bias. The percentage of people who reported childhood health problems decreased, in contrast with expectations, with age group. This underreporting of childhood health problems among older people was higher in lower educational groups. ${ }^{17}$ Persons under 25 were excluded as the effect of childhood health on both the socioeconomic status in adult life and on adult health, is expected not to be completed in younger persons. This resulted in a study population of 2511 respondents.

In the LS-SEHD, several indicators of socioeconomic status and (self reported) health were measured. In this analysis the highest level of education attained was used as indicator of socioeconomic status. Students were classified on the basis of their current course. Educational level was divided into seven categories (university, higher vocational, intermediate general, intermediate vocational, lower general, lower vocational, primary school). Self reported health at adult age was indicated by perceived general health, measured by the question "How do you rate your health in general?" A dichotomous variable was constructed ("very good, good" versus "fair, sometimes good and sometimes bad, bad").

Childhood health was assessed retrospectively by answering of the following question: "Did you suffer from a severe disease or accident in childhood?" If the answer was "yes", the subsequent questions were: "Have you been admitted to hospital for that disease(s) or accident(s)?" and "What was your age at the time of hospital admission?" Only hospi-

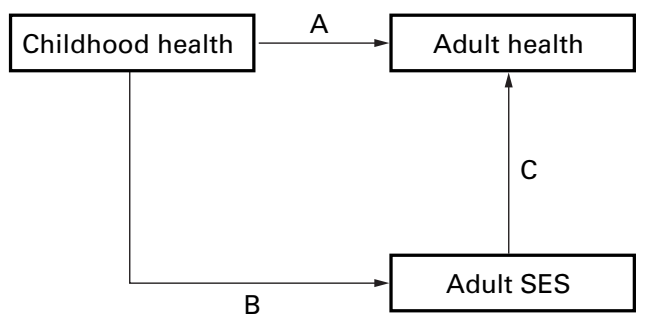

Figure 1 Research model of the contribution of childhood health to the explanation of soioeconomic inequalities in health in early adult life.
KEY POINTS

- Risk of early adult health problems is higher among people who reported health problems in childhood.

- Risk of severe diseases and hospital admissions in childhood is higher in the lower educated groups.

- Selection on health in childhood may account mainly for the contribution of childhood health to socioeconomic inequalities in early adult health.

- A policy aimed at reducing socioeconomic health differences should be considered to improve health in childhood.

tal admissions at the age of 24 or under were included as hospital admissions at older ages were not regarded as "childhood" health. Childhood socioeconomic status was indicated by the occupational level of the father at the respondents' age of 12 . Fathers' occupational level was classified according to the Erikson, Goldthorpe, and Portocarero (EGP) scheme ${ }^{18}$ into five categories: higher grade professionals, lower grade professionals and routine nonmanual, self employed, high and low skilled manual, and unskilled manual. Figure 1 shows the research model.

The analysis is carried out in two steps. The first step in the analysis was to study the association between childhood health and adult health (A), as well as that between childhood health and adult socioeconomic status (B). Only when childhood health characteristics are related to both health and socioeconomic status in early adulthood, can they play a part in the explanation of SEHD in early adult life. Logistic regression was used to estimate these associations. The demographic variables age (five year categories), sex, marital status, degree of urbanisation, and religious affiliation were added as confounders to the model. The reduction in deviance resulting from the inclusion of childhood health characteristics (A) or educational level (B) was used as an overall statistical test of their effect.

The next step in the analysis was to establish the association between adult socioeconomic

Table 1 Men and women, aged 25-34, current educational level, current health, and health in childhood

\begin{tabular}{lcc}
\hline & Number & $\%$ \\
\hline Current educational level & & \\
1 (low) & 131 & 5.3 \\
2 & 492 & 20.0 \\
3 & 320 & 13.0 \\
4 & 528 & 21.4 \\
5 & 274 & 11.1 \\
6 & 485 & 19.7 \\
7 (high) & 235 & 9.5 \\
Current perceived general health & 2127 & 85.7 \\
(Very) good & 354 & 14.3 \\
Less than good & 1927 & 77.4 \\
Severe disease in childhood & 563 & 22.6 \\
$\quad$ No & & \\
Yes & 2120 & 85.2 \\
Hospital admission in childhood & 368 & 14.8 \\
$\quad$ No & \\
Yes & $210 w e r$ \\
\hline
\end{tabular}

^Educational levels: 1 primary school; 2 lower vocational; 3 lower general; 4 intermediate vocational; 5 intermediate general; 6 higher vocational; 7 university. 
Table 2 Men and women, aged 25-34, less than good current perceived general health by health in childhood*, odds ratios (95\% CI)

\begin{tabular}{llll}
\hline Health in childhood & $\begin{array}{l}\text { Odds ratio less than good current } \\
\text { perceived general health }\end{array}$ & RDt & p Value \\
\hline Severe disease in childhood $\ddagger$ & $2.21(1.72,2.84)$ & $36.22(\mathrm{df} 1)$ & $\star \star$ \\
Hospital admission in childhood $\neq$ & $2.29(1.72,3.04)$ & $30.06(\mathrm{df} 1)$ & $\star \star$ \\
\hline
\end{tabular}

${ }^{\star}$ Controlled for sex, age, martial status, religious affiliation, and degree of urbanisation. tReduction in deviance compared with model without severe disease/hospital admission in childhood.

$\star \star \mathrm{p}<0.01$

$\ddagger$ Reference group is no severe disease/no hospital admission in childhood.

Table 3 Men and women, aged 25-34, health in childhood by current educational levelt, odds ratios $(95 \% \mathrm{CI})$

\begin{tabular}{lll}
\hline Current educational level $\neq$ & $\begin{array}{l}\text { Odds ratio severe disease in } \\
\text { childhood }\end{array}$ & $\begin{array}{l}\text { Odds ratio hospital admission in } \\
\text { childhood }\end{array}$ \\
\hline 1 & $2.34(1.39,3.91)$ & $3.78(2.06,6.95)$ \\
2 & $1.55(1.03,2.34)$ & $2.28(1.38,3.79)$ \\
3 & $1.40(0.90,2.18)$ & $1.80(1.03,3.13)$ \\
4 & $1.31(0.87,1.97)$ & $1.81(1.09,3.00)$ \\
5 & $1.56(1.00,2.44)$ & $1.80(1.02,3.18)$ \\
6 & $1.35(0.91,2.03)$ & $1.50(0.90,2.50)$ \\
7 & 1 & 1 \\
RD $\$$ & $11.87(\mathrm{df} 6)$ & $22.96(\mathrm{df} 6)$ \\
p Value & $\star$ & $\star \star$ \\
\hline
\end{tabular}

†Controlled for sex, age, marital status, religious affiliation and degree of urbanisation.

$\ddagger$ Educational levels: 1 primary school; 2 lower vocational; 3 lower general; 4 intermediate vocational; 5 intermediate general; 6 higher vocational; 7 university.

$§$ Reduction in deviance compared with model without educational level.

${ }^{\star} \mathrm{p}<0.05 ;{ }^{\star \star} \mathrm{p}<0.01$.

status and adult health (C) and to estimate the contribution of childhood health to the explanation of this relation, thereby using logistic regression models. Health differences between socioeconomic groups are expressed in odds ratios with $95 \%$ confidence intervals. The highest level was used as the reference category. Childhood health characteristics were added separately to a model with educational level and confounders only. The contribution of childhood health was measured by the percentage reduction in the odds ratios of educational level compared with the first model. Again the reduction in deviance caused by the inclusion of childhood health characteristics was used as an overall statistical test of their effect.

\section{Results}

Table 1 represents the distribution of respondents according to educational level, health in childhood, and health in early adulthood. As the results for men and women were highly comparable, the analyses do not distinguish between the sexes.

Table 2 shows the association between childhood health and health in early adulthood ( $\mathrm{A}$ in fig 1). Respondents reporting severe disease or hospital admission in childhood reported more health problems at adult age. For example, the odds ratio for a "less than good" perceived general health is 2.21 among respondents that reported a severe disease in childhood.

Table 3 shows the association between childhood health and educational level (B in fig 1). Lower educational levels show a statistically significantly higher risk of severe disease and hospital admission in childhood. For example, the odds ratio for severe disease in childhood is 2.34 among respondents who only attended primary school, and for hospital admission it is 3.78 .

To estimate the contribution of childhood health to the explanation of educational differences in early adult health a multiple logistic regression analysis was carried out. Severe disease and hospital admission in childhood were added to a model that includes educational level and confounders only. Table 4 shows the results.

Educational differences in perceived general health decrease when childhood health is added to the model. For example, the odds ratio of the lowest educational group for a "less than good" perceived general health is 8.77 . When severe disease in childhood is added to the model the odds ratio decreases to 7.98. This means that an estimated $10 \%$ of the increased risk of the lowest educational group can be attributed to this factor. With respect to the inclusion of hospital admission, a reduction in odds ratio of $13 \%$ was found in the lowest educational group. In the other educational groups the reduction in odds ratio varies between $5 \%$ and $10 \%$ with respect to severe disease and between $7 \%$ and $9 \%$ with respect to hospital admission. The reduction in deviance resulting from the inclusion of childhood health characteristics to the model with educational level and confounders was statistically significant.

Table 4 Men and women, aged 25-34, less than good current perceived general health by current educational level*, contribution of health in childhood, odds ratios (95\% CI)

\begin{tabular}{|c|c|c|c|c|c|}
\hline \multirow[b]{2}{*}{$\begin{array}{l}\text { Current educational } \\
\text { levelt }\end{array}$} & \multirow{2}{*}{$\begin{array}{l}\begin{array}{l}\text { Model A (education }+ \\
\text { confounders) }\end{array} \\
\text { Odds ratio (CI) }\end{array}$} & \multicolumn{2}{|c|}{$\begin{array}{l}\text { Model } A+\text { severe disease in } \\
\text { childhood }\end{array}$} & \multicolumn{2}{|c|}{$\begin{array}{l}\text { Model } A+\text { hospital admission in } \\
\text { childhood }\end{array}$} \\
\hline & & Odds ratio $(C I)$ & $\begin{array}{l}\text { Difference with } \\
A(\%) \neq\end{array}$ & Odds ratio $(C I)$ & $\begin{array}{l}\text { Difference with } \\
A(\%) \neq\end{array}$ \\
\hline 1 & $8.77(4.50,17.05)$ & $7.98(3.99,15.74)$ & 10 & $7.76(3.87,15.27)$ & 13 \\
\hline 2 & $4.86(2.70,8.74)$ & $4.67(2.59,8.40)$ & 5 & $4.56(2.51,8.15)$ & 8 \\
\hline 3 & $3.00(1.59,5.57)$ & $2.89(1.54,5.40)$ & 5 & $2.87(1.53,5.35)$ & 7 \\
\hline 4 & $2.21(1.20,4.05)$ & $2.15(1.16,3.93)$ & 5 & $2.11(1.14,3.85)$ & 8 \\
\hline 5 & $1.89(0.96,3.66)$ & $1.80(0.92,3.48)$ & 10 & $1.80(0.93,3.51)$ & 9 \\
\hline 6 & $1.57(0.83,2.91)$ & $1.52(0.80,2.82)$ & 8 & $1.53(0.81,2.85)$ & 7 \\
\hline 7 & 1 & 1 & - & 1 & - \\
\hline $\mathrm{RD} \$$ & & $77.078(\mathrm{df} 6)$ & & $73.993(\mathrm{df} 6)$ & \\
\hline $\mathrm{p}$ Value & & $\star \star$ & & $\star \star$ & \\
\hline
\end{tabular}

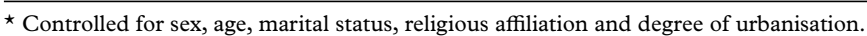

† Educational levels: 1 primary school; 2 lower vocational; 3 lower general; 4 intermediate vocational; 5 intermediate general; 6 higher vocational; 7 university.

† (OR model A - OR model A + severe disease, hospital admission in childhood) $/($ OR model A - 1) $100 \%$.

$\int$ Reduction in deviance compared with a model without educational level.

${ }^{\star \star} \mathrm{p}<0.01$. 


\section{Discussion}

The contribution of childhood health to the explanation of socioeconomic inequalities in health was studied in the age group 25-34 years. An association between health in childhood and health in early adulthood could be established. The risk of early adult health problems is approximately two times higher among people who reported health problems in childhood, as compared with those reporting no such problems. A (statistically significant) negative association between childhood illness and adult socioeconomic status is found: the risk of health problems in childhood in the lowest educational group is approximately 2.5 times higher for severe diseases and approximately fourfold for hospital admission. Childhood health explains approximately $5 \%$ to $10 \%$ of the increased risk of having a "less than good" perceived general health.

The analyses were repeated for occupational level. As the results were highly comparable to those obtained from analyses for educational level (results not shown), they do suggest that the results can be generalised to other SES indicators.

When interpreting the data, there are some limitations of the study design that need some consideration. Firstly, the contribution of childhood health could be underestimated because of reporting bias. Reporting bias is probably caused by omitting to report (or forgetting) events from the past, such as diseases or hospital admissions. We compared our prevalence rates of childhood illness with other, prospective, studies in similar age cohorts (born between approximately 1955 and 1970). Unfortunately we are not aware of such studies in the Netherlands. Results from the offspring of the first British birth cohort study and results from the second British birth cohort study show prevalence rates of $20 \%$ for hospital admission ${ }^{19}$ and $15 \%$ and $19 \%$ for chronic conditions and injuries respectively. ${ }^{14} 20$ Results for the United States were comparable. ${ }^{21}$ Our results (for example, 23\% childhood illness) seem not to be in conflict with these figures, and serious underestimation has probably not occurred.

Secondly, the choice for perceived general health as the indicator for adult health status may cause bias, because perceived general health as subjective health indicator may be more related to reported childhood illness than objective health measurements are, because of a common background factor as, for example, a tendency to complain. In that case, the contribution of childhood health would be overestimated. To explore this hypothesis we carried out the analysis on the basis of a more objective health indicator: suffering from one or more chronic condition at the time of the survey. The results with respect to chronic conditions were comparable to those for perceived general health (results not shown). This indicates that our conclusion applies also to less subjective health indicators. Our results should be verified further using, for example, mortality data. At present however we are not able to check this, because the number of deaths in this age group in the LS-SEHD cohort is too small to study mortality differences.

As mentioned earlier, the contribution of childhood health can be partly interpreted in terms of social causation (through unfavourable circumstances in childhood) and partly in terms of health selection. To distinguish between these two mechanisms we adjusted for the causation mechanism by taking into account the occupation of the father as the indicator for childhood socioeconomic status. As stated above, a reduction in odds ratio of approximately $5 \%$ to $10 \%$ was found when the association between educational level and "less than good" perceived general health was corrected for childhood illness. After occupation of the father had been adjusted for, we found similar percentages reduction in odds ratio when childhood illness was added to the model. Thus, the contribution of health in childhood cannot be explained by the occupation of the father. This means that the importance of the social causation mechanism is probably small. Consequently, selection on health in childhood seems to account mainly for the contribution of childhood health to the explanation of socioeconomic health differences in early adult life. We tested this by estimating the relation between health in childhood and educational level, adjusted for occupation of the father. Adjusting for occupation of the father did not change the relation significantly. This confirmed our hypothesis. Although the literature suggests a minor role of direct selection on health in childhood in the explanation of socioeconomic health differences in adult life, ${ }^{62-24}$ different studies have reached different conclusions. For example, Wadsworth ${ }^{7}$ reported a direct effect of health status on intergenerational mobility, but Lundberg $^{613}$ found no evidence that severe childhood illness increases the risk of downward intergenerational mobility. However, the effect of childhood illness on social mobility is probably seriously underestimated in Lundberg's study. This underestimation is probably caused by a very low prevalence rate for childhood illness (approximately $2 \%$ ), based on a question on childhood illness that regards the family and not the interviewees themselves. Other evidence of the absence of direct selection is based on the effect of "childhood" health measured among 15 to 20 year olds on the socioeconomic status between ages $21-26 .{ }^{6}$ This period obviously is very short in view of social mobility. Moreover, the influence of childhood health is likely to also appear earlier in life. Our results suggest that it seems possible that the role of direct selection is small but relevant, at least in early adult life. The role of the selection mechanism should be explored in further research.

In this study the reductions in odds ratio vary between approximately $5 \%$ and $10 \%$ when severe disease or hospital admission were added to a model that includes educational level and health in early adulthood. As mentioned before, results from two British studies about the contribution of childhood health were ambiguous. ${ }^{14}{ }^{15}$ Our results show 
that health in childhood plays a part in the explanation of socioeconomic health differences in early adult life. This contribution, although not very large, cannot be ignored. Our results emphasise the need for efforts to improve health in childhood in a policy that aims at reducing SEHD in the total population. For example, preventive child and school health services can play a part in monitoring the educational career of children who are severely ill or are admitted to hospital. To achieve the World Health Organisation's target number 1 to reduce health inequalities by $25 \%,{ }^{25}$ intervening in childhood health may be helpful.

The LS-SEHD is supported financially by the Ministry of Welfare, Public Health and Cultural Affairs. It forms part of the GLOBE study ("Gezondheid en Levensomstandigheden Bevolking Eindhoven en omstreken"). The GLOBE study is performed by the Department of Public Health of Erasmus University Rotterdam, in collaboration with the Public Health Services of the city of Eind Valkices of the city of Eindhoven, the region of GeldropValkenswaard, and the region of Helmond. The GLOBE study as a whole is supported financially by the Praevention Fund, the Ministry of Welfare, Public Health and Cultural Affairs, the Sick Fund Council ("Ziekenfondsraad"), the Netherlands OrganisaCommission for the Chronically Ill, and the Erasmus University Commission Funding: The LS-SEHD is financially supported by the Ministry of

Conflicts of interests: none.

1 Blaxter M. The health of the children. London: Heinemann Educational Books, 1981.

2 Rose G. Reflections on the changing times. BMF 1990;301: 683-7.

3 Spencer NJ. Child poverty and deprivation in the UK. Arch Dis Child 1991;66:1255-7.

4 Townsend P, Davidson N. Inequalities in health (The Black Report). London: Penguin, 1982.

5 Wadsworth $M$. Inter-generational differences in child health. In: IOCS Occasional paper. Measuring sociodemographic change. London: HMSO, 1985:no 43:51-8.

6 Lundberg O. Childhood living conditions, health status, and social mobility: a contribution to the health selection debate. Eur Soc Rev 1991;7:149-62.
7 Wadsworth MEJ. Serious illness in childhood and its association with later-life achievement. In: Wilkinson RG, ed. Class and health: resear
Tavistock, 1986:1-20.

8 Douglas JWB, Early hospital admissions and later disturbances of behaviour and learning. Develop Med Child Neurol 1975;17:456-80.

9 Wolfe BL. The influence of health on school outcomes. Med Care 1985;23:1127-38

10 Walker A. Unqualified and underemployed: handicapped young people and the labour market. London: Macmillan, 1982. (Cited in: Power C. A review of child health in the 1958 birth cohort: National Child Development Study. Paediatric Perinat Epidemiol 1992;6:81-110.)

11 Koivusilta L. Rimpelä A, Rimpelä M. Health status: does it predict choice in further education? $\mathcal{F}$ Epidemiol Community Health 1995;49:131-8.

12 Pless IB, Cripps HA, Davies JMC, Wadsworth MEJ. Chronic physical illness in childhood: psychological and social effects in adolescence and adult life. Dev Med Child Neurol 1989;31:746-55.

13 Lundberg O. Class position and health: social causation or selection? Stockholm: University of Stockholm, 1988.

14 Power C, Manor O, Fox AJ, Fogelman K. Health in childhood and social inequalities in health in young adults. fournal of the Royal Statistical Society 1990;153:17-28.

15 Kuh DJL, Wadsworth MEJ. Physical health status at 36 years in a British national birth cohort. Soc Sci Med 1993; 37:905-16.

16 Mackenbach JP, Mheen $\mathrm{H}$ van de, Stronks K. A prospective cohort study investigating the explanation of socioeconomic inequalities in health in the Netherlands. $S_{o c} S_{c i}$ Med 1994;38:299-308.

17 Mheen $\mathrm{H}$ van de, Stronks K, Looman CWN, Mackenbach JP. Recall bias in self-reported childhood health problems: differences by age and educational level. Sociology of Health and Illness (in press).

18 Erikson R, Goldthorpe JH, Portocarero L. Intergenerational class mobility and the convergence thesis: England, France and Sweden. Br F Sociol 1983;34:303-42.

19 Wadsworth MEJ. Generation differences in child health. Early Child Development and Care 1986;25:1-10.

20 Power C, Peckham C. Childhood morbidity and adulthood ill health. F Epidemiol Community Health 1990;44:69-74.

21 Starfield B, Katz H, Gabriel A, et al. Morbidity in childhood - a longitudinal view. $N$ Engl f Med 1984;310:824-9.

22 Power C, Fogelman K, Fox AJ. Health and social mobility during the early years of life. Quarterly fournal of Social during the early years of
Affairs $1986 ; 2: 397-413$.

23 Wilkinson RG. Socioeconomic differentials in mortality: interpreting the data on size and trends. In: Wilkinson RG, ed. Class and health: research and longitudinal data. London: Tavistock, 1986:1-20.

24 Blane D, Davey Smith G, Bartley M. Social selection: what does it contribute to social class differences in health? Sociology of Health and Illness 1993;15:1-15.

25 World Health Organization. Targets for health for all. Copenhagen: WHO Regional Office for Europe, 1985. 